\title{
Preoperative Prediction of Difficult Laparoscopic Cholecystectomy Using a Scoring System
}

A.M.E.Daly, R.Elnagar, A.A.Shoulah and M.M.Rezk

General Surgery Dept., Faculty of Medicine, Benha Univ., Benha, Egypt

E-Mail: A.Daly@gmail.com

\begin{abstract}
Difficulties Throughout laparoscopic cholecystectomies are not extraordinary as a rule surgery, Throughout laparoscopic cholecystectomy [LC]. This ponder pointed on assess part of preoperative demographic What's more sonographic tolerant information will foresee specialized foul challenges Throughout LC. This current contemplate might have been conveyed ahead 100 patients anguish from symptomatic cholelithiasis by and large surgery Branch during Benha college doctor's facilities. Every one patients in this contemplate were subjected of the following, history taking, clinical examination, schedule research center investigations Furthermore abdominal ultrasonography. We evaluated the system viewing preoperative predictive Components of troublesome LC [preoperative scoring system]. Intraoperative Conclusion as viewing those Emulating agent parameters: occasion when made for surgery, bile/stone spillage, harm should cystic conduit or cystic artery, transformation should open cholecystectomy. We resorted of the traditional four port procedure [two $10 \mathrm{~mm}$ and two $5 \mathrm{~mm}$ ports] utilizing those north american plan. For preoperative evaluation, as stated by Randhawa What's more Pujahari scoring framework we predicted preoperatively that $67 \%$ might pasquinade easily, $28 \%$ will a chance to be difficult, Furthermore 5\% from claiming patients Around this consider predicted on experience exceptionally troublesome LC Also might transformation to open cholecystectomy. Intraoperative outcome, 67 patients who were predicted should a chance to be simple looking into surgery, for which 56 were really easy, inasmuch as nine from claiming them turned out with a chance to be troublesome once surgery, What's more 2 patients were exceptionally troublesome LC. However, the $28 \%$ from claiming situations predicted to a chance to be difficult, 20 patients were really difficult, 2 turned out with be exceptionally difficult, Furthermore 6 underwent simple surgery. There were 5 [5\%] situations predicted will be exceptionally troublesome looking into surgery, Anyhow you quit offering on that one [1\%] pasquinade easily, in turn instance [1\%] might have been troublesome What's more 3 [3\%] really were exceptionally troublesome. Done our study, An solid measurable relationship might have been discovered the middle of preoperative assessment prediction Furthermore was troublesome LC. The preoperative scoring may be statistically Furthermore clinically a great test for foreseeing the agent result over LC.
\end{abstract}

Keywords: Prediction, Laparoscopic Cholecystectomy, Complications.

\section{Introduction}

Gallbladder infection may be An regular reason for upper abdominal pain, Also intense cholecystitis is a standout amongst the The majority as a relatable point purposes behind healing facility confirmation On patients with intense abdominal ache. Imaging assumes a paramount part in the administration for cholecystitis in light of gallbladder malady generally need a great prognosis furnished finding Furthermore oversaw economy happen speedily [13].

Cholecystectomy will be those medicine about decision for symptomatic gallstones On account it removes those organ that contributes to both those shaping of gallstones and the difficulties outcome from them [2].

Laparoscopic agent methods need revolutionized surgery for huge numbers points of interest: An more modest What's more An more cosmea incision, diminished blood loss, decreased postoperative sit tight Furthermore pain, diminished danger of surgery Furthermore anesthesia related complications, which is reflected in patient's sooner profit to typical schedule existence Furthermore worth of effort exercises. [5].

Actually in the display era, the laparoscopic surgeon, amidst such a considerable propel clinched alongside laparoscopy, ought to have low edge to transformation will open strategy in the event from claiming trouble. Transformation rates from claiming $2 \%-15 \%$ need been accounted in distinctive distributed arrangement. Those challenging gallbladder is those the vast majority normal 'difficult' laparoscopic surgery continuously performed by general surgeons around the universe and the possibility particular case that puts those tolerant during noteworthy hazard. It will be critical to think those distinctive clinical, radiological parameter Also particular predictor that provide for exactly prediction of challenging LC, which not just aides Previously, tolerant guiding as well as serves the specialist will get ready finer to intraoperative challenges expected on make encountered [1].

However, those requirement for transformation will be not a disappointment or a muddling in any case basically An venture made to guarantee tolerant security Also Abstain from difficulties [8].

This study meant on assess part of preoperative demographic What's more sonographic tolerant information with anticipate specialized foul challenges Throughout laparoscopic cholecystectomy.

\section{Patients and methods}

This prospective study was carried on 100 patients suffered from cholelithiasis, admitted to general Surgery department of Benha university hospital, Benha, Egypt. All of them underwent elective LC, and were operated by experienced laparoscopic surgeons.

\subsection{Patient selection 2.2 Inclusion Criteria}


All patients with gall bladder stones, Patients of all ages and both gender will be included in the study.

\subsection{Exclusion criteria}

GB carcinoma, peritonitis, acute pancreatitis, pregnancy, liver cirrhosis.

All patients in the study were subjected to the following:

\section{Preoperative evaluation}

A. Clinical assessment: including full history taking, thorough clinical examination with emphasis on signs of acute cholecystitis or history of hospitalization for acute cholecystitis.

B. Laboratory investigations including: complete blood count, coagulation profile , liver function tests e.g.; Liver enzymes, bilirubin level either total or direct, kidney function tests as blood urea and serum creatinine, blood glucose level and CRP.
C. Imaging study: Abdomen ultrasonography [US] in all cases: Positive findings of the abdominal U/S were listed including liver condition, gall bladder shape [distended or contracted], gall bladder wall thickness, stones [size], presence of pericholecystic collection, impacted Stone, and common bile duct diameter, lumen, and contents.

All of the Patients Subjected to the scoring system which was defined by [15] that was used for categorization and grading difficulty level of LC, the scores were given on[1] history: gender, age, and history of hospitalization for acute cholecystitis; [2] clinical examination: abdominal scar, BMI [body weight [kg] / height [m], and palpable GB; [3] sonological findings: pericholecystic collection, wall thickness of GB, impacted stones. Table [1].

Table (1) Preoperative risk factors [15] .

\begin{tabular}{|c|c|c|c|}
\hline History & & & Max score \\
\hline Age & $<50(0)$ & $>50(1)$ & 1 \\
\hline Sex & Female(0) & Mate (1) & 1 \\
\hline $\begin{array}{l}\text { IUD } \\
\text { hospitalization }\end{array}$ & $\operatorname{No}(0)$ & Yes (4) & 1 \\
\hline $\begin{array}{l}\text { Clinical } \\
\text { BMI }\end{array}$ & $<25$ & $\begin{array}{c}>25-27.5(1) \\
>27.5(2)\end{array}$ & 2 \\
\hline Palpable GB & $\mathrm{No}(0)$ & Yes (1) & 1 \\
\hline $\begin{array}{l}\text { Abdominal } \\
\text { scar } \\
\text { Sonography }\end{array}$ & $\operatorname{No}(0)$ & $\begin{array}{c}\text { Infraumbilical(1) } \\
\text { Supraumbilical (2) }\end{array}$ & 2 \\
\hline $\begin{array}{l}\text { Wall } \\
\text { thickness }\end{array}$ & $\operatorname{Thin}(0)$ & Thick $>4$ nun $(2)$ & 2 \\
\hline $\begin{array}{l}\text { Impacted } \\
\text { stones }\end{array}$ & $\mathrm{No}(0)$ & Yes (1) & 1 \\
\hline $\begin{array}{l}\text { Pericholecysti } \\
\text { c collection }\end{array}$ & $\operatorname{No}(0)$ & Yes (1) & 1 \\
\hline
\end{tabular}

One-day prior to surgery, the scores were provided for each patient and categorized as easy, difficult or very difficult if scores $\leq 5,6-10$ or 11-15 respectively. Intraoperative; each patient was categorized as easy if operative time was $\leq 60$ minute or difficult if operative time was> 60 minute or conversion to open cholecystectomy or common bile duct injury. Table (2).

Surgery were done using $\mathrm{CO} 2$ pneumoperitoneum with $10 \mathrm{~mm} \mathrm{Hg}$ pressure and using standard two $5 \mathrm{~mm}$ and two $10 \mathrm{~mm}$ ports. The timing was noted from the first port site incision until the last port closure. All the intraoperative events were recorded. The following operative parameters were recorded for all the patients undergoing LC:

- Time taken for surgery

- Bile/stone spillage

- Injury to cystic duct or cystic artery

- Conversion to open cholecystectomy.

Table (2) Easy/difficult criteria.

\begin{tabular}{lccc}
\hline Factors & Easy & Difficult & Very difficult \\
\hline Time taken (minutes) & $<60 \mathrm{~min}$ & $60-120 \mathrm{~min}$ & $>12 \mathrm{C}) \mathrm{min}$. \\
Bile stone spilla2e & No & Yes & Yes \\
injury to duct or artery & No & Duct only & Both \\
Conversion to open & No & No & Yes \\
\hline
\end{tabular}


To avoid bias in surgical outcome, all patients enrolled in study were operated by experienced laparoscopic surgeons without knowing the score of preoperative prediction for difficult laparoscopy.

\subsection{Statistical methods}

\subsection{Data management}

The clinical data were recorded on a report form. These data were tabulated and analysed using the computer program SPSS (Statistical package for social science) version 20 to obtain descriptive and analytical statistics

\section{Results}

The age distribution among studied patients, it was $77 \%$ were $\leq 50 \mathrm{y}$ and $23 \%$ were $>50 \mathrm{y}$. The age ranging from 20 years to 62 years with a mean of 41.9 years (SD \pm 10.09 ). Of 100 patients, $82 \%$ were females and $18 \%$ were males. regarding history of acute cholecystitis, the patients of no history for acute cholecystitis were 75 , while those of a history of acute cholecystitis were $25 \%$. the clinical data parameters as BMI was distributed amoung 100 cases as; 58\% were within normal range, $30 \%$ were obese and $12 \%$ were overwieght.As regarding to scar of previous abdominal surgery, it was found that there were $36 \%$ with Scar of previous abdominal surgery, 11 cases of them had supraumbilical scar, those with Infraumbilical scar were 25 pateints and $64 \%$ had no history of previous abdominal surgery.

The results of U/S findings, cleared that ; Gall bladder wall thickness was more than $4 \mathrm{~mm}$ in $28 \%$ of patients, while $16 \%$ of them had pericholecystic collection ; also uls show $24 \%$ had impacted stones as shown in Table (3) .

On preoperative evaluation, According to Randhawa and Pujahari scoring system we can preoperative predicte that $67 \%$ may pass easliy, $28 \%$ will be difficult, and $5 \%$ of patients among this study predicted to undergo very difficult LC and may be converted to open cholecystectomy as shown in Table (4).

Intraoperative outcome, 67 patients which were predicted to be easy on surgery, of which 56 were actually easy, wherease nine of them turned out to be difficult on surgery, and 2 were very difficult LC. However, the 28 cases predicted to be difficult, 20 were actually difficult, 2 turned out to be very difficult, and 6 underwent easy surgery. There were 5 cases predicted to bo very difficult on surgery, but one case passed easliy, another case was difficult,and 3 actually were very difficult. The relation between the prediction level of the patients preoperatively and the actual outcome intraoperative of the cases is shown in Table (5).

Five $(5 \%)$ cases were converted to open cholecystectomy ; 4 (4\%) patients were predicted to be difficult /very difficult, while only one (1\%) patient was predicted tob easy and converted to open cholecystectomy. Table (6).

Recevier operating characteristic (ROC) curve for prediction of intraoperative outcome based on preoperative score for difficult/ very difficult versus easy cases at cutoff point reater than 5 and area under the curve (AUC) of 0.79 , with $95 \%$ confidence interval (CI) $=0.69-.0 .89$, showed sensivity of 70.3 , specificity 88.9, positive predictive value (PPV) 78.8 , negative predictive value (NPV) 83.6, and accuracy 82, as showen in Table (7) and Fig (1).

Moreover, ROC curve for very difficult versus easy cases AUC of 0.78, with 95\% CI=0.67-0.89, showed sensivity of 66.7, specificity 90.3, PPV 78.6, NPV83.6, and accuracy 82.1. ROC curve for difficult versus easy cases AUC of 0.62 , with $95 \% \mathrm{CI}=044-0.80$, showed sensivity of 26.3, specificity 98.2, PPV 80.0, NPV83.6, and accuracy 83.3. Table (8).

Table (3) Distribution of the studied group.

\begin{tabular}{lcc}
\hline \multicolumn{1}{c}{ Preoerative risk factors } & (No $(\mathbf{1 0 0}$ & \% \\
\hline Age mean $\mathbf{\text { SDD }}$ (range) & $(41.9 \pm 10.09(20-62$ & \\
$\leq \mathbf{5 0 y}$ & 77 & 77.0 \\
$\mathbf{> 5 0}$ & 23 & 23.0 \\
Gender & & \\
Male & 18 & 18.0 \\
Female & 82 & 82.0 \\
H.O.H & & \\
Yes & 25 & 25.0 \\
No & 75 & 75.0 \\
BMI median & $(24.0(23.0-28.75$ & \\
$<\mathbf{2 5}$ & 58 & 58.0 \\
$\mathbf{2 5 - 2 7 . 5}$ & 12 & 12.0 \\
$>\mathbf{2 7 . 5}$ & 30 & 30.0 \\
Scar & & \\
Subraumbilical & 11 & 11.0 \\
No scar & 64 & 64.0 \\
Infraumbilical & 25 & 25.0 \\
Palpable GB & & \\
Yes & 23 & 23.0 \\
No & 77 & 77.0 \\
\hline
\end{tabular}




\begin{tabular}{lll}
\hline Table (3) Continue & & \\
\hline Wall thickness & & \\
$>\mathbf{4} \mathbf{~ m m}$ & 28 & 28.0 \\
$\mathbf{4} \mathbf{~ m m}$ & 72 & 72.0 \\
Pericholecystic collection & & 16.0 \\
Yes & 16 & 84.0 \\
No & 84 & \\
Impacted stone & & 24.0 \\
Yes & 24 & 76.0 \\
No & 76 & \\
\hline
\end{tabular}

Table (4) preoperative prediction of difficulty of LC.

\begin{tabular}{lcc}
\hline $\begin{array}{l}\text { Perioperative } \\
\text { prediction }\end{array}$ & No. & \% \\
\hline V. difficult & 5 & 5.0 \\
Difficult & 28 & 28.0 \\
Easy & 67 & 67.0 \\
\hline
\end{tabular}

Table (5) correlation between preoperative prediction and the outcome.

\begin{tabular}{|c|c|c|c|c|c|c|c|}
\hline \multirow{2}{*}{$\begin{array}{l}\text { Perioperative prediction } \\
\text { Intraoperative }\end{array}$} & \multicolumn{2}{|c|}{ V. difficult (5) } & \multicolumn{2}{|c|}{ Difficult (28) } & \multicolumn{2}{|c|}{ Easy (67) } & \multirow{2}{*}{$\begin{array}{l}\text { Statistical } \\
\text { test (FET) }\end{array}$} \\
\hline & No & $\%$ & No & $\%$ & No & $\%$ & \\
\hline Very difficult & 3 & 60.0 & 2 & 7.1 & 2 & 3.0 & 44.98 \\
\hline Difficult & 1 & 20.0 & 20 & 71.4 & 9 & 13.4 & \\
\hline Easy & 1 & 20.0 & 6 & 21.4 & 56 & 83.6 & \\
\hline
\end{tabular}

Table (6) Conversion to open procedure and preoperative prediction.

\begin{tabular}{lccccc}
\hline $\begin{array}{l}\text { Conversion to open } \\
\text { bprocedure }\end{array}$ & \multicolumn{2}{c}{ Yes (5) } & No (95) & $\begin{array}{l}\text { Statistical } \\
\text { test (FET) }\end{array}$ \\
\hline Preop prediction & No & $\%$ & No & $\%$ & \\
\hline Very difficult \&Difficult & 4 & 80.0 & 30 & 31.2 & 1.64 \\
Easy & 1 & 20.0 & 66 & 68.8 & \\
\hline
\end{tabular}

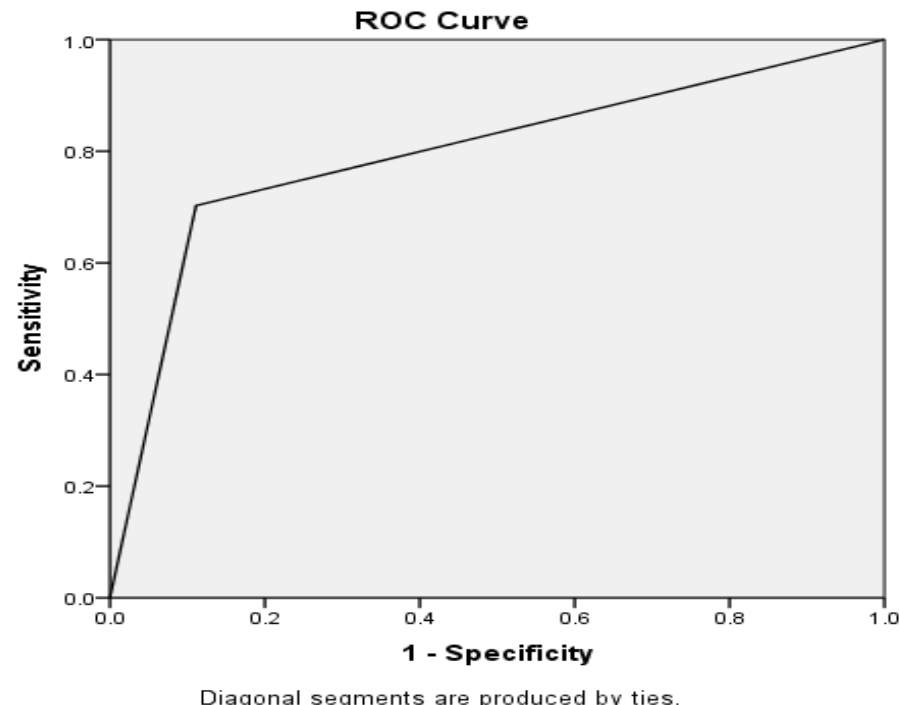

Fig (1) Recevier operating characteristic curve and its area under curve for prediction of intraoperative outcome based on preoperative score for difficult/ very difficult versus easy.

Table (7) Recevier operating characteristic prediction of intraoperative outcome based on preoperative score for difficult/ very difficult versus easy. 


\begin{tabular}{|c|c|c|c|c|c|c|}
\hline \multirow{2}{*}{$\begin{array}{l}\text { Intraop } \\
\text { Preop prediction }\end{array}$} & \multicolumn{2}{|c|}{$\begin{array}{l}\text { Very difficult \& } \\
\text { Difficult (37) }\end{array}$} & \multicolumn{2}{|c|}{ Easy (63) } & \multirow[t]{2}{*}{$\begin{array}{c}\text { Statistical } \\
\text { test }(\mathbf{x} 2)\end{array}$} & \multirow[t]{2}{*}{ P value } \\
\hline & No & $\%$ & No & $\%$ & & \\
\hline Very difficult \&Difficult & 26 & 70.3 & 7 & 11.1 & 36.9 & $<0.001 * *$ \\
\hline Easy & 11 & 29.7 & 56 & 88.9 & & \\
\hline $\operatorname{AUC}(95 \% \mathrm{CI})$ & \multicolumn{6}{|c|}{$0.796(0.697-0.895)$} \\
\hline Sensitivity & \multicolumn{6}{|c|}{70.3} \\
\hline Specificity & \multicolumn{6}{|c|}{88.9} \\
\hline PPV & \multicolumn{6}{|c|}{78.8} \\
\hline NPV & \multicolumn{6}{|c|}{83.6} \\
\hline Accuracy & \multicolumn{6}{|c|}{82.0} \\
\hline
\end{tabular}

Table (8) ROC curve for prediction of intraoperative outcome based on preoperative score

\begin{tabular}{lccc}
\hline & $\begin{array}{c}\text { Very difficult and } \\
\text { Difficult \&easy }\end{array}$ & Difficult \&easy & Very difficult \&easy \\
\hline (AUC (95\% CI & $(0.796(0.697-0.895$ & $(0.785(0.678-0.892$ & $(0.625(0.448-0.801$ \\
Sensitivity & 70.3 & 66.7 & 26.7 \\
Specificity & 88.9 & 90.3 & 98.2 \\
PPV & 78.8 & 78.6 & 80.0 \\
NPV & 83.6 & 83.6 & 83.6 \\
Accuracy & 82.0 & 82.1 & 83.3 \\
\hline
\end{tabular}

\section{Discussion}

Period may be An danger component to challenging gb surgery. )9). In the display series, the larger part of patients were in the age class from claiming $\leq 50$ a considerable length of time (77 patients) and just $23 \%$ (23 cases) were $>50$ a considerable length of time. In the introduce study, we found no huge $(\mathrm{p}=0.31)$ relationship between period and the was troublesome level of surgery. This Might a chance to be due to the little test span of the examine number alternately conceivably due to in length surgical knowledge.

Male sexual orientation makes those surgery was troublesome (14). Transformation rate Furthermore essentially higher mortal sin accounted in male sexual orientation (3). In the exhibit study, there were 82 female and 18 male patients. Of 18 males, nine $(50 \%)$ of them were predicted preoperative with have simple surgery. Following surgery, five (55. 5\%) really were not difficult on surgery, two (22. 3\%) situations turned out with was troublesome procedure, another two (22. $3 \%$ ) patients turned out should a chance to be exceptionally troublesome operation. Along these lines we found noteworthy correspondence the middle of male sex and the challenging level for surgery over univariate dissection for intraoperative Conclusion ( $\mathrm{p}=$ 0. 001).

The patients who require hospitalization to reapeted strike for intense cholecystitis convey additional possibilities about challenging LC Furthermore conversion, most likely owing should thick adhesions at calot's triangle Furthermore gb fossa (3). In this study, we found to a chance to be statistically huge for prediction for was troublesome LC On univariate examination intraoperative Conclusion $(\mathrm{p}=0.001)$.

Viewing obesity, laparoscopic surgery is was troublesome owing should Different factors, for example, such that port placement to large patients detract more extended time owing of the thick abdominal wall, analyzation at calot's triangle will be likewise actually was troublesome owing of the dark anatomybecause from claiming over the top intraperitonial fat, Furthermore there may be challenge in the control for instruments through a exorbitantly thick abdominal divider (16). Over our study, BMI more stupendous over 27.5 might have been found will be An huge figure for prediction for challenging LC clinched alongside univariate dissection intraoperative Conclusion ( $p=0.001$ ).

Supra Also Infraumbilical scar, implication of past abdominal operations, might prompt adhesions available the middle of viscera or omentum Furthermore abdominal divider. There might a chance to be possibilities from claiming damage should these structures Throughout insertion about firstport, and the hazard from claiming transformation might have been reportedto be higher (11). Done our study, abdominal scar wad discovered with a chance to be statistically insignificantin both univariate What's more multivariate analyses from claiming preoperative Furthermore intraoperative conclusions with danger figure.

Unmistakable gb might have been discovered to make predictor for challenging LC, clinically unmistakable gb might be expected to expanded GB, mucocele about GB, thick- walled alternately owing will adhesions between $\mathrm{gb}$ and the omentum(4). In the exhibit study, 23 patients required unmistakable GB, 15 about them required a troublesome system then afterward surgery. Unmistakable gb found will be statistically significantinunivariate dissection for preoperative Furthermore intraoperative results with hazard component ( $\mathrm{p}=0.003$ and 0.001 , individually ).

Increasd thickness for gb divider may be connected with challenging analyzation of the gb from its bed; thick gb divider might make grasping What's more 
control for gb difficult, Furthermore this likewise makes the analyzation In calot's triangle and the gb couch on a chance to be troublesome Also breaking points the degree about anatomic definition (7). Clinched alongside our study, we discovered noteworthy connection between those gb divider thickness and the challenge level about surgey On both univariate What's more multvariate analyses of preoperative Also intraoperative results for hazard element $(\mathrm{p}=0.003$ Furthermore 0. 002, Also $\mathrm{p}=0.001$ What's more 0. 002, individually.

Pericholecystic accumulation might have been discovered to make a predictor about troublesome LC (6). Other investigations discovered that pericholecystic gathering might have been discovered to a chance to be inconsequential calculate in the challenge level from claiming LC (15). Clinched alongside our study, we found no critical correspondence the middle of pericholecystic gathering and the trouble level about surgery over both univariate Also multivariate analyses for preoperative What's more intraoperative conclusions.

Affected stone In the neck of gb postures a portion specialized foul issues in LC, due to distension about GB, with thick gb divider. It may be challenging should graspthe gb neck will permit sufficient withdrawal on perform dismemberment toward calot's triangle (12). In our study, affected stone In the neck for gb might have been discovered will be statistically critical done univariate Investigation of preoperative Also intraoperative conclusions with danger faktor $(p=0.001$ What's more 0.003, individually ).

Change rate might have been accounted On written works the middle of 2 Also $15 \%$ (10). Different investigations news person that, challenging cases would associatedwith a change rate about $25 \%$ (1). To our study, those convresion rate might have been $5 \%$, due to thick bond during calot's triangle ( three body of evidence $3 \%$ ), What's more two $2 \%$ patients with uncontrolled dying. Overall, three patients of them were male inasmuch as two patients were female.

From our study, we discovered that the amount ofcase predicted should a chance to be difficult/very troublesome on preoperative assessment were 33(33\%) patients, of which 26 (26\%) were difficult/ exceptionally troublesome looking into surgery, inasmuch as seven (7\%) were turned to make easy, Furthermore likewise four patients were changed over with open.

Those instance predicted will make simple once preoperative assessment were 67 (67\%), of which 56 $(56 \%)$ were really simple inasmuch as elevin (11\%) patients turned out will make difficult/ exceptionally troublesome with respect to surgery, Furthermore special case (1\%) might have been changed over will open.

Those $\mathrm{x}$ might have been 55. 34 (>19. 537), which donates those Exceedingly statistically huge ( $\mathrm{p}=0.001)$ connection between preoperative score What's more intraoperative score for LC patients, with the goal the tolerant with simple preoperative score basically will need not difficult intraoperative score and also blacks.

\section{Conclusion}

Those preoperative scoring is statistically Also clinically a great test to foreseeing the agent result done LC In this way, the patent who may be taking score 0-5 predicted with a chance to be simple LC, Anyway who is taking score 6 or additional predicted with need was troublesome alternately exceptionally troublesome LC ,with plausibility from claiming transformation will open surgery uncommonly with score more than 10 .

\section{References}

[1] Alponat, CK .Kum, BC. Koh, A. Rajnakova, PM Goh. Predictive factors for conversion of laparoscopic cholecystectomy. World J Surg, Vol.21, PP.629-33, 1997.

[2] R.Arora, B.Arora, Six anatomical landmarks for safe Laparoscopic Cholecystectomy. International Journal of Enhanced Research in Medicines \& Dental Care, ISSN;2349-1590 Vol. 1 (10), pp. 30-34,2014.

[3] L .Bouarta, A. Schneider, H. Feussner, N. Navab, HU. Lemake, PP. Jonker, Prediction of intreoperative complexity from preoperative patient data for laparoscopic cholecystectomy. ArtifIntell Med, Vol.52, PP.169-176,2011.

[4] RC .Chen, MH. Liu, HY. Tu, WT. Chen, CS. Wang, LC. Chiang,The value of ultrasound measurmentofgallbladderwallthicknessinpredictingla paroscopicoperabilityprior to cholecystectomy. ClinRadiol, Vol.50, PP.570-572,1995.

[5] Chmiel, L .Cierpka, Laparoscopic cholecystectomyadvantages and disadvantages. WiadLek, Vol.56(34), PP.167-171,2003.

[6] PS .Dhanke, SP. Vagne, Factors predicting difficult lap laparoscopic cholecystectomy: a single institution experience. Int J Stud Res, Vol.4, PP.3-7,2014.

[7] GM .Fried, JS. Barkun, HH. Sigman, I .Joseph, D .Clas, J .Garzon, Factors determining conversion to laparotomy in patients undergoing laparoscopic cholecystectomy. AM J Surg, Vol.167, PP.35$39,1994$.

[8] NA .Gómez, J .Zapatier, PE .Vargas. Established advantages of minilaparotomy cholecystectomy versus laparoscopic cholecystectomy. Cir Esp, Vol.79(2), PP.130-131,2006.

[9] MD. Heng-HuiLein, Ching-Shui Huang , Male gender: Risk factor for severe symptomatic cholelithiasis. World J Surg, Vol.26, PP.598601,2002.

[10] P.Hollington, G.J.Toogood, R.T. Padbury, A prospective randomized trial of day-stay only versus overnight-stay laparoscopic cholecystectomy. Aust NZ J Surg, Vol.69, PP.841843, 1999.

[11] A.Hussain, Difficult laparoscopic cholecystectomy: current evidevce and strategies of management. SurgLaparoscEndoscPercutan Tech; vol.21, PP.211-217,2011.

[12] P .Lal, PN .Agarwal, VK. Malik, AL. Chakravarti. A difficult laparoscopic cholecystectomy that 
requires conversion to open procedure can be predicted by preoperative ultrasonograghy. JSLS, Vol.6, PP.59-63,2002.

[13] OJ.O'Connor , MM.Maher , Imaging of Cholecystitis. AJR, Vol.196, PP. 32-50,2011.

[14] DP. O'Leary, E .Myers, D .Waldron, JC. Coffey, Beware the contracted gallbladder-ultrasonic predictor of conversion. Sureon, Vol.11, PP.187190,2013.

[15] JS. Randhawa, AK.Pujahari, Preoperative prediction of lap chole: a scoring method. Indin $\mathbf{J}$ Surg, Vol.71, PP.198-201,2009.

[16] M. Rosen, F .Brody, J.Ponsky, Predictive factors for conversion of laparoscopic cholecystectomy. AM J Surg, Vol.184, PP.254-258,2002. 